\title{
Decision Matrix Analysis of Impact Sounding Test Method to Determine Interlayer Condition of Concrete Bridge Deck
}

\author{
Cristina Amor Rosales, ${ }^{1,2}$ Hyun Jong Lee, ${ }^{1}$ Wonjae Kim, ${ }^{1}$ and Chang kyu Park ${ }^{1}$ \\ ${ }^{1}$ Department of Civil and Environmental Engineering, Sejong University, Chungmu-gwan, 98 Gunja-dong, Gwangjin-gu, \\ Seoul 143-747, Republic of Korea \\ ${ }^{2}$ Department of Civil and Environmental Engineering, Batangas State University, Batangas City, Philippines
}

Correspondence should be addressed to Hyun Jong Lee; hlee@sejong.ac.kr

Received 25 May 2017; Accepted 13 August 2017; Published 1 November 2017

Academic Editor: Zhou Zhi

Copyright (C) 2017 Cristina Amor Rosales et al. This is an open access article distributed under the Creative Commons Attribution License, which permits unrestricted use, distribution, and reproduction in any medium, provided the original work is properly cited.

\begin{abstract}
This study focused on the analysis of the frequency spectra of impact sounding test performed on composite slabs with different interlayer condition. Distinct and consistent characteristics of the frequency spectra were observed from the impact signals. The consistency of results for bonding condition at varying temperature was also investigated. Results of laboratory tests were compared to different bonding condition observed in the field. Finally, a proposed decision matrix analysis was presented and successfully identified the interface bonding condition. The proposed decision matrix is composed of four zones characterizing each interlayer condition based on the features of impact signals. Field and laboratory assessment conform to decision matrix result.
\end{abstract}

\section{Introduction}

Bonding between pavement layers is an important factor for long term performance of asphalt concrete $(\mathrm{AC})$ pavements and for the durability of bridge deck slabs. A decrease in the bonding strength at the interface between the AC deck pavement and Portland cement concrete (PCC) deck plate and increase in pavement deflection caused by traffic loading may result in accelerated fatigue damage in the pavement [1-3]. In addition, debonding between a water proofing layer and bridge deck may cause more serious problems to the bridge deck. Water and/or deicing salt could easily penetrate into the concrete deck resulting in deterioration of concrete slab and corrosion of reinforcements [3, 4]. Therefore, appropriate interlayer bonding is essential to achieve the long term durability of the AC-PCC bridge deck pavement.

Evaluating the amount of debonding area developed in the bridge deck is very important to determine proper timing and methods for repair or rehabilitation. However it is not an easy task because debonding cannot be determined by visual inspection of the pavement, especially at the early stages of deterioration. Therefore, nondestructive tests (NDTs) such as impact echo (IE), ground penetrating radar (GPR), and sounding methods have been applied to determine the condition of bridge deck pavements. American Society for Testing and Materials (ASTM) released guidelines and methods for detecting delamination using sounding (ASTM 4580), infrared thermograph (ASTM 4788), and GPR (ASTM D6087) [5-7]. These approaches focused on concrete bridge deck condition but not on the interlayer debonding problems. The second Strategic Highway Research Program (SHRP-2) was recently conducted to evaluate the efficiency of available NDTs in determining delamination and debonding of pavement infrastructures [8]. GPR methods displayed limitations on determining delamination in shallow depth or on wet conditions and detailed boundaries of damaged area at fast survey [9]. Previous study indicated that GPR tests succeeded in detecting $33 \%$ of simulated debonded sections and could only qualitatively identify severely debonded areas with presence of moisture [10]. The limitation of IE/SASW tests is greatly affected by the temperature of AC pavements and the slow-walking speed limits [8]. The IE method was also found to be limited to certain deterioration size and shallow delamination which generates vibration frequency [11]. 


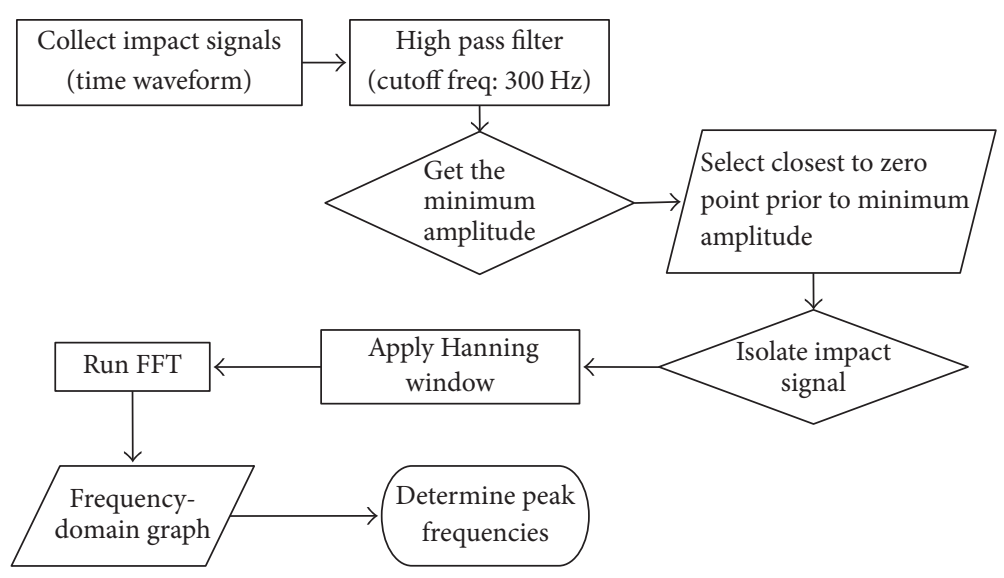

FIGURE 1: Impact sounding preprocessing algorithm.

In addition to the GPR and IE methods, impact sounding has long been used to detect deterioration and debonding problems of AC covered PCC bridge deck plate. Impact sounding involves tapping of hammer and dragging chains on pavement surface and interpreting the sound produced. Ringing sound corresponds to bonded section whereas the dull or hollow sound corresponds to debonded section. The impact sounding approach is relatively simple and has been practically used in the field. The major deficiencies of the impact sounding are time consuming for large area survey and inspector-dependent interpretations to testing results. Different studies using signal processing techniques interpret impact sounds of damaged and deteriorated structures [1215]. The damaged portion of structures using the impact sound method was determined by analyzing the frequencydomain spectra of impact sound data at sensitive ranges [14]. Despite accurate results obtained from these studies, none of these studies focused on the interlayer condition of composite pavement but on overall assessment of the bridge. In addition, the analysis time and cost in performing the tests are relatively expensive and impractical for small projects needing assessment. Therefore, this study proposed a simple and direct sounding signal analysis of determining interlayer condition of pavement system.

The major objective of this study was to perform comparative analysis of impact sounding parameters between deteriorated and nondeteriorated interlayer of composite slab. The specific objective was to establish mathematical expression of impact sounding parameters which will identify the interlayer condition of composite slab with AC surface. Following a traditional impact sounding method, impact sounds were collected and transformed in frequency domain and the whole spectra were analyzed to differentiate normal from deteriorated conditions. Finally a quantitative approach of evaluating the interlayer condition was proposed.

\section{Impact Sound Analysis}

Impact sounding test involves hammer hitting or chain dragging in which the sounds produced are analyzed by inspectors during the testing or after sound recording.
Real-time evaluation of impact sounds is subjected to humanerror and perception of the sound if the bridge deck produces ringing or hollow sound. In ASTM 4580-12, the standard method for measuring delamination in concrete bridge decks by sounding, impact sounding samples are taken within 3 milliseconds after the tap. The hollowness or defective sound can be detected at significant component frequency range of 300 to $1,200 \mathrm{~Hz}$.

Michigan Department of Transportation [16] designed a delamination detection device which records the impact sounds and the signal is recorded. The recorded signal is passed through a band-pass filter with cutoff frequencies 300 and $1200 \mathrm{~Hz}$ and played back to the inspector for delamination determination. The method eliminates the traffic noise but the inspector still performs subjective identification of damage.

Henderson et al. [12] developed an automatic chain dragging system (ACDS) which can record, analyze, and evaluate the concrete bridge deck condition. The system records chain drag sound using microphone and filter it based on linear prediction coefficients (LPC). The filter process is done by inverting the LPC of the signal from solid concrete. This study also showed that, between delaminated and sound concrete, significant difference is observed at $1 \mathrm{kHz}$ to $6 \mathrm{kHz}$ of frequency spectra. If the tested concrete is solid and sound, the output will be clear or "white" whereas if delamination occurs, it would change. This study found that the frequency range of defects on concrete bridge deck extends up to $5 \mathrm{kHz}$.

From these studies, two significant points were noted: (1) frequencies below $5,000 \mathrm{~Hz}$ characterize hollow sound and (2) characterization of frequency band provides training parameters to quantify the degree of damage. Thus, in this study, these two findings served as fundamental basis for feature extraction of impact sounds to determine the interlayer debonding of concrete decks.

The data analysis process used in this study is presented in Figure 1. Impact sound signals were filtered using high pass with cutoff frequency of $300 \mathrm{~Hz}$ to eliminate the frequency caused by traffic noise. To further eliminate noise from original signal, 10-millisecond length impact signals were isolated manually by selecting the closest zero-amplitude 


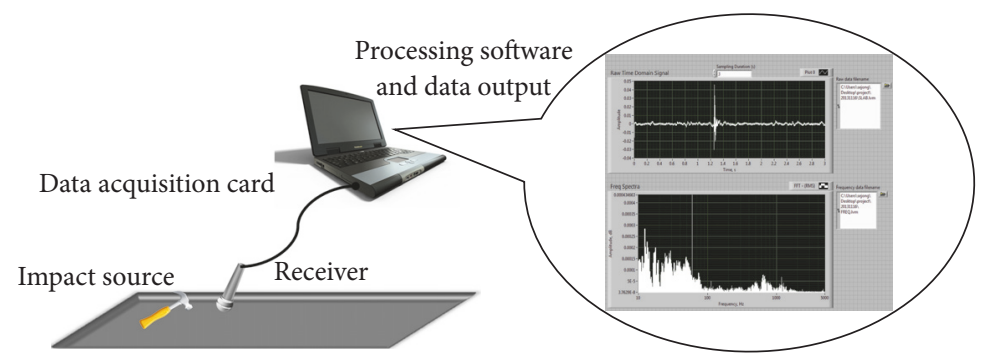

FIGURE 2: Sounding signal acquisition process.

point prior to the minimum amplitude. The sliced length of 10 milliseconds was based on the decay rate of the impact sound signals observed in the initial test and previous studies on impact sound duration [17, 18]. This signal is isolated and Hanning window is applied prior to FFT conversion. As commonly employed in sound signal analysis, fast Fourier transform was performed to convert waveform data to frequency spectra $[15,19]$.

\section{Feature Extraction}

Contrary to impact echo, ultrasonic wave, and surface wave analysis, sounding test analysis considers broad frequency characteristics of impact sound. It is noted that impact signal classified as transient signals is a nonstationary signal in which the whole duration is analyzed as a whole entity with no regard of how they vary with time. Hence, it is considered to have a finite amount of "energy" (amplitude squared integrated over time) and the spectrum is most readily expressed in terms of "energy spectral density" [20]. Simply put, the analysis of impact signals considers the whole range of frequency spectra.

Previous sounding studies $[5,12,16]$ mentioned that identification of hollow sound relies on the features of frequency spectra. Sets of impact sounding data are "trained" to identify damaged condition which is similar to human's logicbased identification. Several studies successfully applied this method specifically in tunnel linings [14] and tile [21, 22] as these studies focus on bonding quality of materials. Based on impact sounding studies mentioned, two features, sound pressure level and frequency spectra range of $300 \mathrm{~Hz}$ to $5000 \mathrm{~Hz}$, are common features that identify damage using impact sounding.

In this study, preliminary investigation was performed in the laboratory to confirm how sound pressure level differs with debonded and bonded concrete bridge deck layer. Features of these data are further investigated to extract the most appropriate parameter for quantifying interlayer conditions.

\section{Sounding Signal Acquisition Process}

The signal acquisition process consists of signal source, receiver collecting signal data, processing software for interpretation, and display of the signal data in time and frequency domain. Figure 2 shows the components of signal acquisition process used in this research. The impact device such as a hammer hits a specimen and then the receiver picks up the impact signals. The data acquisition system (DAQ) transfers the signal to the processing software in the computer.

4.1. Impact Sounding Device. In general, an impact device having shorter contact time and smaller contact area is more desirable to produce better accurate sound. In addition, to detect delamination using acoustic sensors, impact source should have high force amplitude, relatively low frequency content, and minimal production of ancillary sound [23]. Depending on the diameter of the impact device, the contact time, $t_{C}$ in $\mu$ s, can be computed given the equation of the American Concrete Institute (ACI):

$$
t_{C}=4.3 D \text {, }
$$

where $D$ is the diameter of the impact equipment in $\mathrm{mm}$. Contact time, $t_{C}$, is the reciprocal of the maximum frequency, $f_{\text {max }}$, the impact equipment can induce as stress wave in the material. It was found from the study of Sansalone and Streett [24] that the amplitudes of stress waves at frequencies below $1.25 / t_{C}$ are sufficient for impact-echo testing. Thus, the maximum frequency, $f_{\max }(\mathrm{kHz})$, that the impact equipment can induce as stress wave in the material can be computed using

$$
f_{\max }=\frac{1.25}{t_{C}}
$$

This maximum frequency can detect a smallest flaw depth, $D_{\text {min }}$, using

$$
D_{\text {min }}=\frac{0.96 C_{\mathrm{p}}}{2 f_{\max }},
$$

where $C_{p}$ is the $\mathrm{P}$-wave speed. The typical value of $C_{p}$ from previous studies $[24,25]$ for concrete ranges from 3,600 to $4,000 \mathrm{~m} / \mathrm{s}$ whereas asphalt is $2,640 \mathrm{~m} / \mathrm{s}$. In the study of Sansalone and Carino [25], impact echo was modified to remove the effect of overlaid material by allowing the small spherical balls (4-12 $\mathrm{mm}$ ) to hit $12.5 \mathrm{~mm}$ diameter steel plate with $4 \mathrm{~mm}$ thickness. In the study, they proposed

$$
T_{d}=0.5\left[\frac{C_{\mathrm{pc}}}{f_{d}}+\frac{C_{\mathrm{pa}}-C_{\mathrm{pc}}}{f_{a}}\right] \text {, }
$$

where $T_{d}$ is the depth of delamination, $C_{\mathrm{pc}}$ is the P-wave speed in cement concrete, $C_{\mathrm{pa}}$ is the P-wave speed in the asphalt 


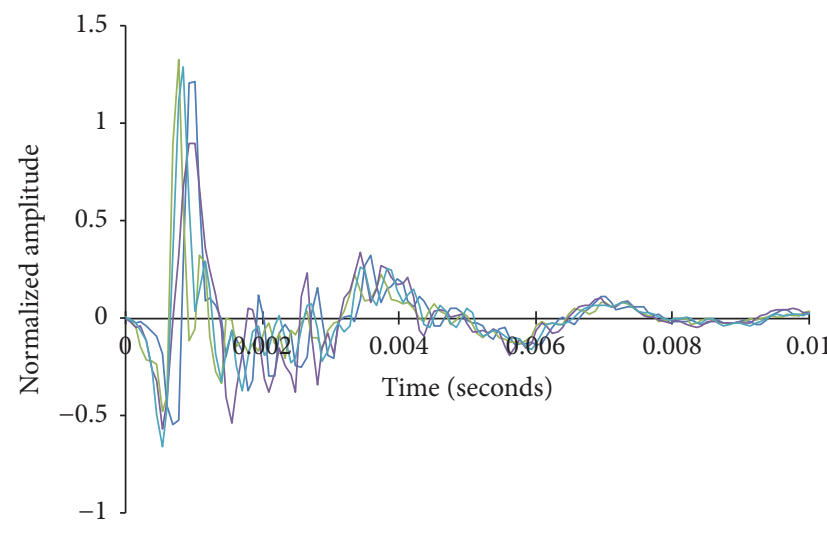

(a)

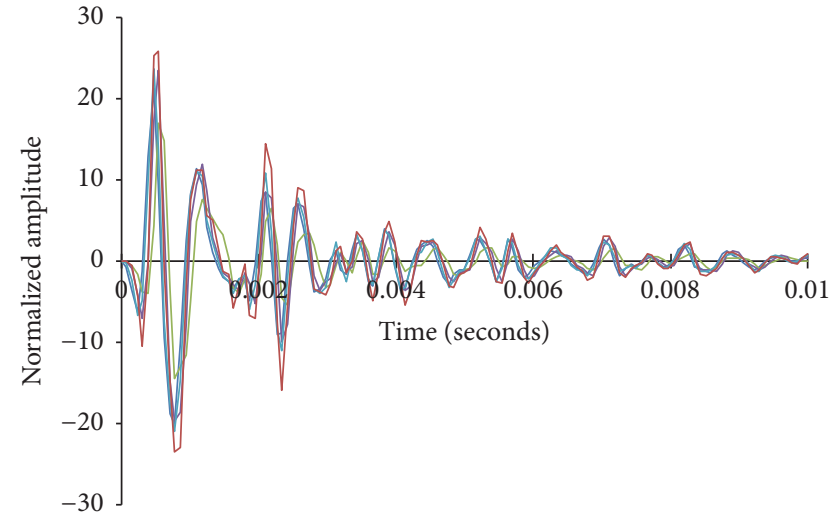

(b)

FIGURE 3: Time waveform of hand-held hammer: (a) $23.45 \mathrm{~mm}$ diameter; (b) $21.5 \mathrm{~mm}$ diameter.

overlay, $f_{d}$ is the corresponding frequency of the depth of the delamination, and $f_{a}$ is the corresponding thickness frequency of the asphalt overlay. In this study, the concerned location is equivalent to the depth of the asphalt overlay; $f_{d}=f_{a}$; thus (3) is applicable to interlayer condition.

Spherical steel ball is the most common device used in impact testing and its diameter dictates the depth of flaw it can analyze. As one of the goals of this research is to provide an economical mobile device, commercially available devices for impact sounding source were used in order to determine the appropriate impact height. Hammers are the most common and economically available tool in the field for sounding; thus different impact head size was selected and evaluated. To obtain the acceptable diameter of impact device, (1), (2), and (3) are combined resulting in the following:

$$
D=\frac{6056 \times D_{\min }}{C_{\mathrm{p}}},
$$

where $D$ is the acceptable impact diameter in $\mathrm{mm} ; C_{\mathrm{p}}$ is the $\mathrm{P}$-wave speed in $\mathrm{m} / \mathrm{s}$ and the typical value of $2640 \mathrm{~m} / \mathrm{s}$ was used; and $D_{\min }$ is the smallest flaw depth $(\mathrm{cm})$ it can detect.

Two commercial hand-held hammers with spherical tip and diameters $23.45 \mathrm{~mm}$ and $21.50 \mathrm{~mm}$ were tested. Figure 3 displayed the time waveform of the two hammers showing that the smaller diameter hammer displays smoothed and consistent data compared with the big one. Also, it can give a minimum contact time of $92.45 \mu$ s resulting in maximum frequency $10,817 \mathrm{~Hz}$. The computed minimum depth it can detect based on (3) is $117 \mathrm{~mm}$ which is slightly higher than desired $80 \mathrm{~mm}$ typical thickness of asphalt concrete overlaid in concrete bridge decks. Since the study focused on the interlayer of composite pavement, the $37 \mathrm{~mm}$ difference provides good flexibility in investigating the interlayer surface of composite pavement. Therefore, in this study, $21.5 \mathrm{~mm}$ diameter of impacting device was used.

4.2. Sound Receiver. In this study, several types of receivers were evaluated to select the most appropriate device for receiving and logging sounding data. Accelerometers typically used for IE tests were excluded in this study because they can be operated only on contact with the surface of pavements. For mobility, a pressure field microphone with a preamplifier (model PCB 378B11) with frequency response of $6.3 \mathrm{~Hz}$ to $125 \mathrm{kHz}$ was selected. In addition to its durability on impact pressure, this microphone sound acquisition is unidirectional, thus reducing the effect of noise in the acquisition process.

The microphone was placed as close to a hitting point as possible to receive desired impact sound signals by minimizing external noise from the environment. From several initial trials, the appropriate vertical and horizontal distances of the microphone from the hitting point were determined as $50 \mathrm{~mm}$ and $5 \mathrm{~mm}$, respectively. The microphone was connected to a National Instruments DAQ (model DAQ 9234) with maximum sampling rate of $51.2 \mathrm{kHz}$. A simple data acquisition and analysis program based on LabView 2013 was developed.

Different sampling frequencies were evaluated to determine the optimal size including the length of samples. Three sampling rates were evaluated: $12.8 \mathrm{kHz}, 25.6 \mathrm{kHz}$, and $51.2 \mathrm{kHz}$. Figure 4 presented the frequency spectra of different sampling frequency and it showed that the spectrum is concentrated on frequencies lower than $5,000 \mathrm{~Hz}$. The sampling frequency of $12.8 \mathrm{kHz}$ providing significant frequency values for the acoustic sounding test without compromising the accuracy of the acquired signal, hence, was used in this study.

\section{Laboratory Tests}

5.1. Specimen Preparation. The three slab specimens, consisting of an AC upper layer and PCC bottom layer, were prepared as shown in Figure 5. The PCC slabs were $60 \mathrm{~cm}$ long, $60 \mathrm{~cm}$ wide, and $20 \mathrm{~cm}$ thick. The first and second PCC slabs had single and double steel reinforcement in the middle of the slab, respectively; the third PCC slab had no reinforcement. These slabs were overlaid with a $5 \mathrm{~cm}$ thick AC layer. Before placing the AC layer, tack coat was applied 


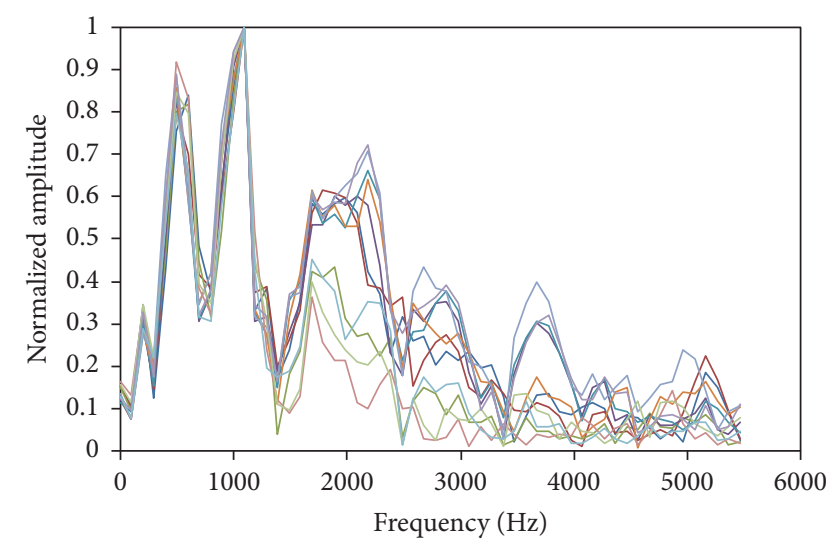

(a)

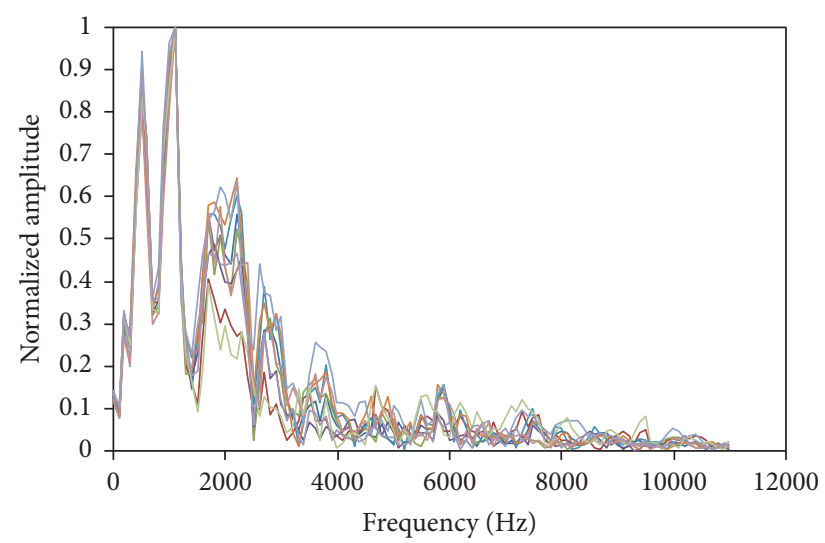

(b)

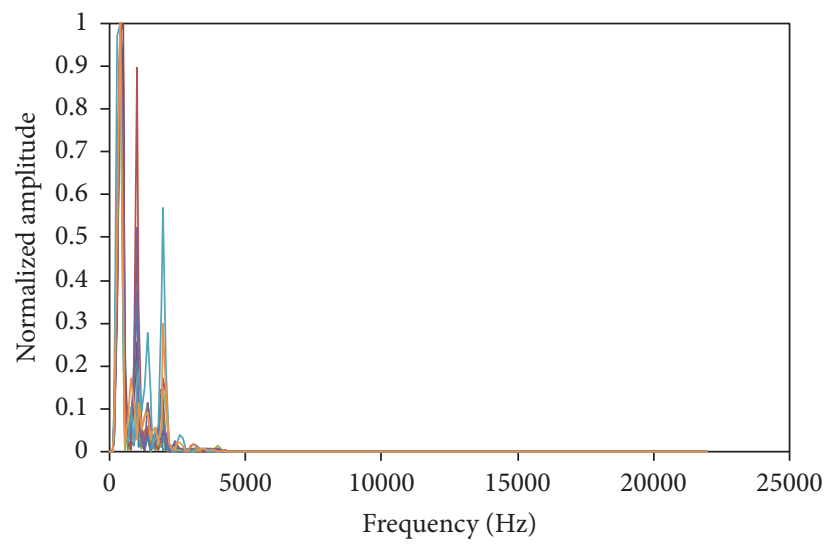

(c)

FIGURE 4: Effect of different sampling rate on frequency spectra: (a) $12,800 \mathrm{~Hz}$; (b) $25,200 \mathrm{~Hz}$; (c) $51,200 \mathrm{~Hz}$.

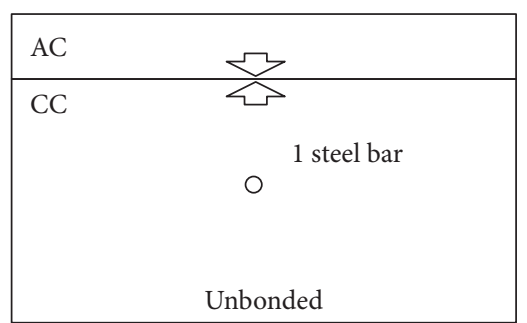

(a) Unbonded with single reinforcement

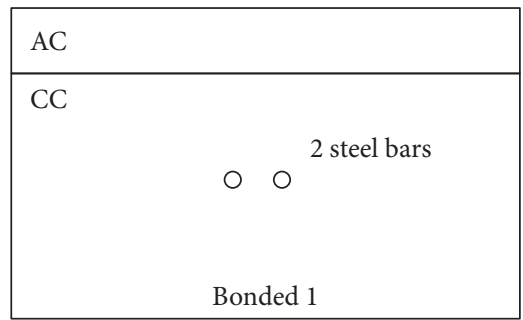

(b) Bonded with double reinforcement

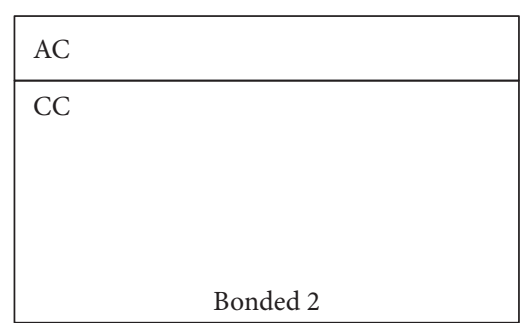

(c) Bonded with no reinforcement

FIGURE 5: Configuration of the slab specimens.

on the surface of the PCC slabs for better bonding. On the other hand, to simulate a completely debonded interlayer condition, plastic tape was covered onto the concrete surface before pouring of asphalt mixtures. Then, the AC layer was carefully torn off from the PCC slab after one week and placed right before the test to keep the interlayer debonded.

5.2. Sounding Test Setup and Procedure. An impact sound test device was used for the slab specimens as shown in Figure 6. A commercially available hammer (612 grams, $21.5 \mathrm{~mm}$ spherical hammer head) was connected to a stable stand and allowed to have a free fall impact on the surface of the asphalt concrete layer. The energy or height of the hammer was controlled by the angle of the hammer on the top. The impact hammer was dropped three times.

\section{Results and Discussion}

6.1. Effect of Interface Condition. The frequency spectra of interlayer condition distinctively showed significant differences in the peak frequency and spectral pattern. In Figure 7, bonding condition showed that the highest amplitude of peak frequency is at $1700 \mathrm{~Hz}$ whereas the unbonded condition highest amplitude peak frequency is at $1100 \mathrm{~Hz}$. The peak 


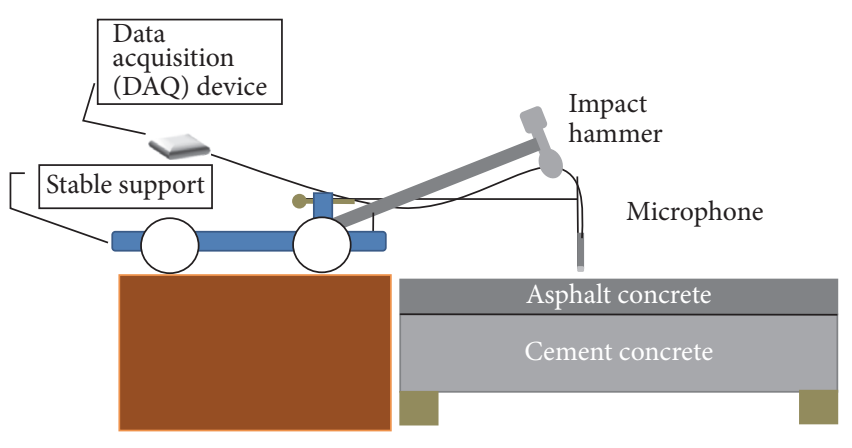

FIgURE 6: Supported slab sounding test setup.

TABLE 1: Observed peaks at frequency spectra for different bonding condition (frequency, $\mathrm{Hz}$ ).

\begin{tabular}{lcc}
\hline $\begin{array}{l}\text { Bonded with double } \\
\text { reinforcement }\end{array}$ & $\begin{array}{c}\text { Bonded with no } \\
\text { reinforcement }\end{array}$ & $\begin{array}{c}\text { Unbonded with } \\
\text { single } \\
\text { reinforcement }\end{array}$ \\
\hline $307 \pm 27$ & $331 \pm 90$ & $455 \pm 29$ \\
$493 \pm 10$ & $491 \pm 10$ & $1087 \pm 25^{*}$ \\
$1166 \pm 32$ & $1168 \pm 31$ & $1724 \pm 35$ \\
$1724 \pm 34^{*}$ & $1722 \pm 34^{*}$ & $2359 \pm 39$ \\
$2311 \pm 113$ & $2358 \pm 40$ & \\
$2924 \pm 294$ & & \\
\hline
\end{tabular}

${ }^{*}$ Highest peak frequency for each bonding condition.

amplitude of the unreinforced bonded slab specimen is $20 \%$ higher than the peak amplitudes of reinforced bonded slab. The amplitude difference between unbonded and bonded slab specimens can be attributed to energy dissipation in the interlayer $[20,26,27]$ resulting in high pressure amplitude measured in the frequency spectra of the unbonded slab specimen.

Table 1 showed the observed average peaks at frequency spectra detected at any bonding condition where the peaks of at least $10 \%$ of the highest peak frequency were identified. Since the bandwidth of the frequency spectra is $100 \mathrm{~Hz}$, it can be generalized that the peaks occurred at similar value and differed where each peak amplitude value was detected. Of the three bonding conditions, only unbonded condition displayed a high amplitude peak greater than $50 \%$ of the highest peak at frequency $455 \pm 2 \mathrm{~Hz}$. This peak became the highest frequency peak of unbonded condition at higher temperature. The effect of temperature is being discussed in the next section.

6.2. Effect of Temperature. Since asphalt concrete is a viscoelastic material, the elastic modulus varies with temperature. Therefore, when considering the parameters, it is very important to determine if the material properties have an effect. Figure 8 showed the frequency spectra of different bonding conditions at different temperature. It was observed that the frequency spectra of bonded sections consistently displayed high multiple peak frequencies above $1,000 \mathrm{~Hz}$. Unbonded section, on the other hand, displayed peak frequencies below 1,100 Hz.
The amplitude at peak in the frequency spectra at the various temperatures, for all slab specimens, was presented in Figure 9. It was observed that the peak amplitude of unbonded condition was always higher than that of the bonded condition. In addition, the amplitude of the peak frequency of the unbonded condition decreased as temperature was increased. It could be mainly due to the fact that asphalt concrete at higher temperature demonstrates more viscous behavior where the material is capable of absorbing more energy.

The frequency peaks of the unbonded slab specimen in Figure 10 showed that the peaks of unbonded condition depend on temperature. At temperature $5^{\circ} \mathrm{C}$ and below, the highest peak was observed at $1,100 \mathrm{~Hz}$, whereas at temperature above $5^{\circ} \mathrm{C}$, the highest peak was at $400 \mathrm{~Hz}$. With regard to bonded condition, frequency peaks remained high above $1,500 \mathrm{~Hz}$.

Although the amplitudes and peak frequencies showed temperature dependence in the unbonded condition, the difference in amplitude and peak frequency between interlayer conditions was significantly high. From these observations, the amplitude and peak frequency were used as features to differentiate between bonded and unbonded conditions.

\section{Field Observations}

Field sounding tests were also performed using similar setup to validate the laboratory results. Yanggok Bridge in Muju, South Korea, will undergo asphalt concrete overlay rehabilitation and hence was selected as suitable area for field validation. The field test was performed before the actual rehabilitation while the other lane of the bridge was operational. Consequently, because of the limited access to the whole concrete bridge deck, only several sections of the bridge identified to have varying condition were selected.

Hitting points were laid at $30 \mathrm{~cm}$ distance along the width of the road starting from point closest to the concrete barrier. Impact sounding samples were also collected near the concrete barrier section with heaved surface. This section was considered to have completely debonded interface. A total of 103 data points were collected from the field observation.

Figure 11 shows that sounding test was performed before removal of asphalt concrete and visual inspection for each point was performed after water jet process was applied. Water jet process was done to completely remove the damaged parts of the concrete deck. By taking its deterioration depth and surface condition, three condition levels were identified for field evaluation as summarized in Table 2. Heaved section was also considered as separate condition since the damage was remarkable from the asphalt surface.

Similar to laboratory test, frequency spectra for the hitting points were plotted and compared with each other according to their condition. Figure 12 presented the combined frequency spectra of points depending on their condition level. It was observed that there was an increase in amplitude value as condition reached deterioration level. In addition, peak frequencies of good and minor conditions occurred at frequencies higher than $1,500 \mathrm{~Hz}$ whereas severe 


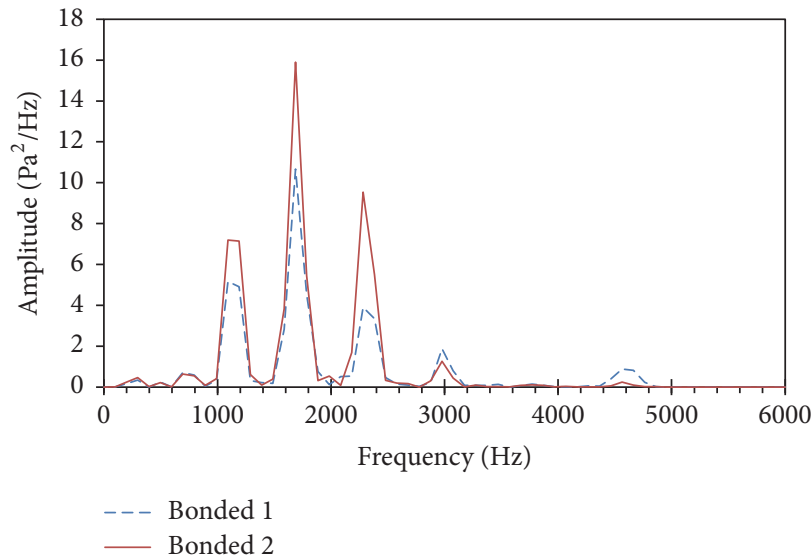

(a)

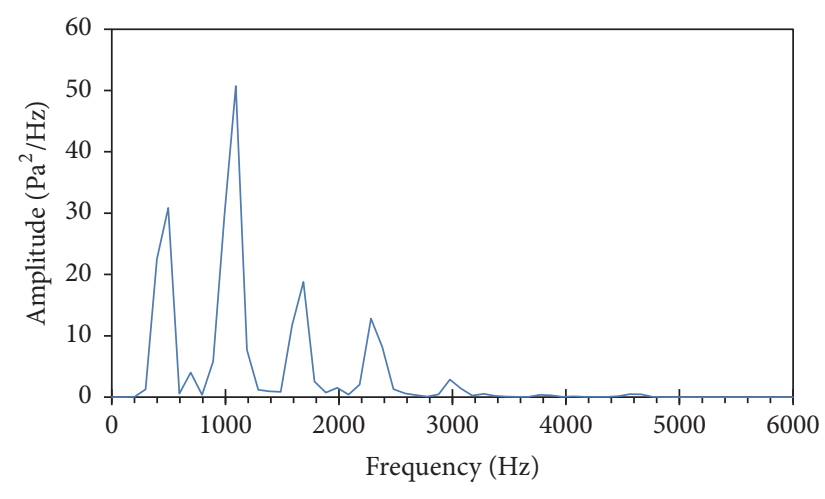

(b)

FIGURE 7: Frequency spectra of slab specimen with different bonding condition: (a) bonded slab specimen; (b) unbonded slab specimens.
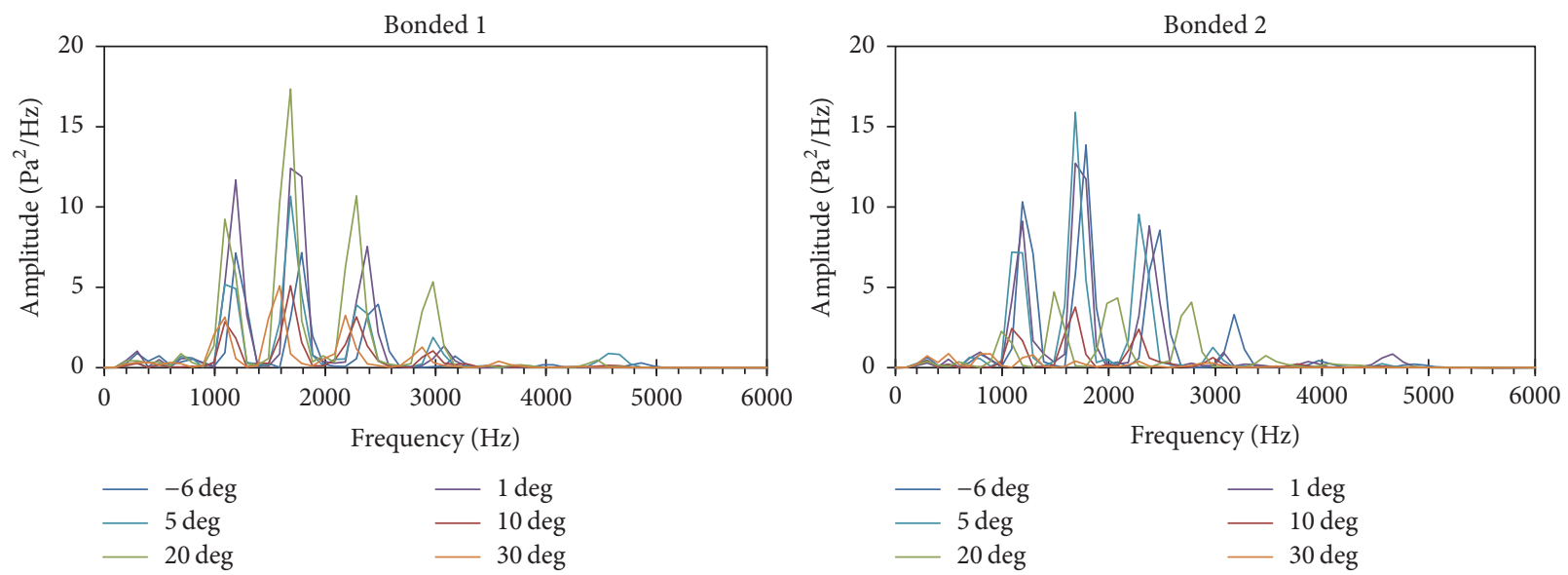

(a)

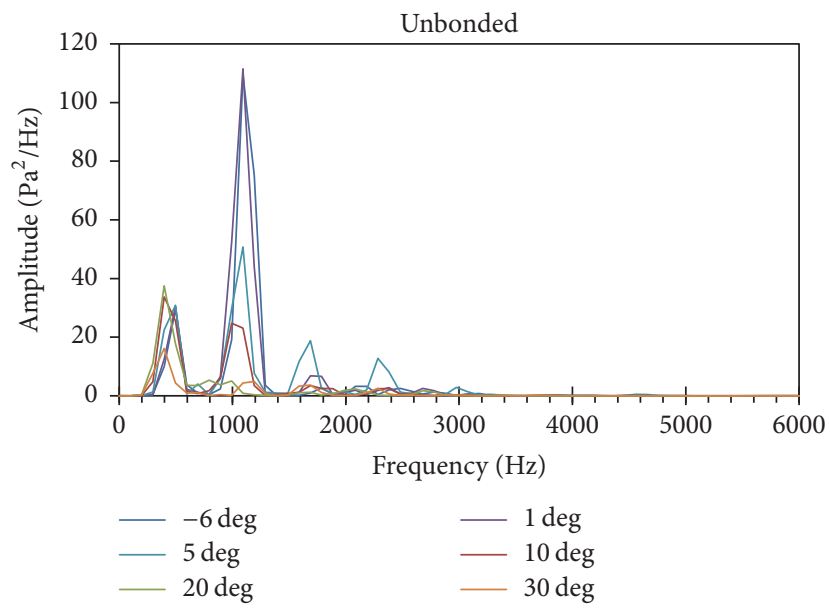

(b)

FIGURE 8: Frequency spectra of different bonding conditions at different temperatures: (a) bonded sections; (b) unbonded section. 


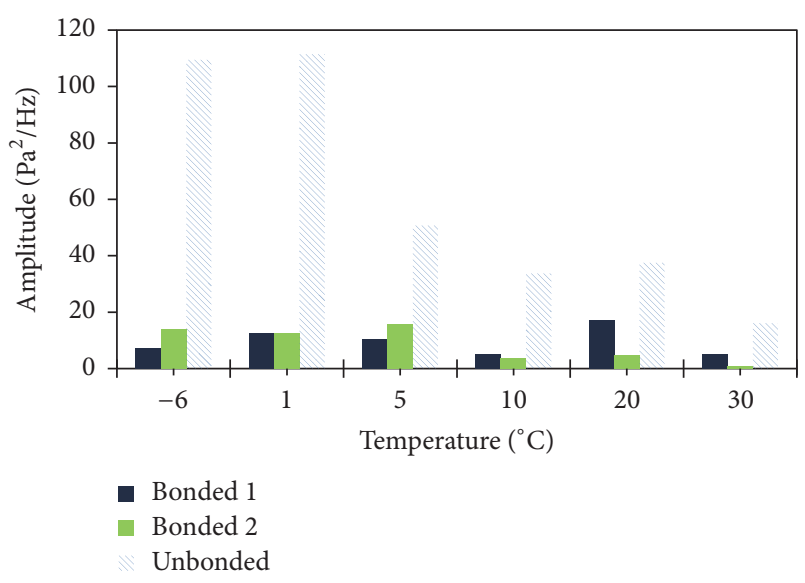

FIGURE 9: Plot of temperature versus amplitude of peak frequency at different bonding conditions.

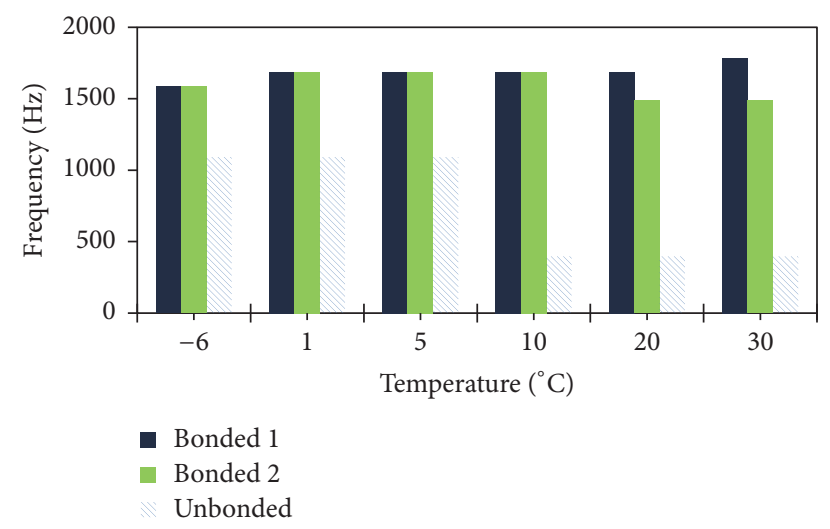

Figure 10: Plot of temperature versus peak frequency at different bonding conditions.

TABLE 2: Condition level description for field evaluation.

\begin{tabular}{ll}
\hline $\begin{array}{l}\text { Condition } \\
\text { level }\end{array}$ & Description \\
\hline Good & $\begin{array}{l}\text { Good condition, no inspected damage on the } \\
\text { interlayer }\end{array}$ \\
\hline Minor & $\begin{array}{l}\text { Minor damage: interface of cement concrete shows } \\
\text { scaling } \\
\text { Cement concrete aggregates are exposed }\end{array}$ \\
\hline \multirow{2}{\text{Severe}}{} & $\begin{array}{l}\text { Deterioration depth is greater than } 25 \mathrm{~mm} \\
\text { Aggregates are removed from the surface } \\
\text { Traces of moisture are remarkable }\end{array}$ \\
\hline Heaved & $\begin{array}{l}\text { Asphalt concrete is heaved and completely detached } \\
\text { from the cement concrete }\end{array}$ \\
\hline
\end{tabular}

condition and heaved sections occurred at frequency less than $500 \mathrm{~Hz}$.

It was also noted that peaks occurred at similar frequencies as summarized in Table 3 wherein, at good and minor condition, peaks occurred at higher frequency value of $2,800 \mathrm{~Hz}$ which was not evident in severe and heaved conditions. Heaved section identified only two peaks at $389 \pm$ $49 \mathrm{~Hz}$ and $682 \pm 69 \mathrm{~Hz}$.
TABLE 3: Observed peaks at frequency spectra for different field condition (frequency, $\mathrm{Hz}$ ).

\begin{tabular}{lccc}
\hline Good & Minor & Severe & Heaved \\
\hline $305 \pm 20$ & $308 \pm 51$ & $331 \pm 56$ & $389 \pm 49$ \\
$489 \pm 9$ & $501 \pm 24$ & $461 \pm 22$ & \\
$707 \pm 28$ & & $650 \pm 68$ & $682 \pm 69$ \\
$1098 \pm 21$ & $1096 \pm 11$ & $1088 \pm 33$ & \\
$1593 \pm 34$ & $1597 \pm 21$ & $1566 \pm 58$ & \\
$2329 \pm 198$ & $2272 \pm 96$ & $2163 \pm 252$ & \\
$2877 \pm 21$ & $2860 \pm 39$ & & \\
\hline
\end{tabular}

\section{Evaluation Matrix of the Interface Condition}

Based on results presented in this study, there were significant observations in the frequency spectra of impact sounds that can distinguish interlayer condition. First, the peak frequency of interlayer condition was always different at any temperature condition and, second, the amplitude of the frequency spectra of unbonded slab specimen was always higher than that of the bonded slab specimen. From these observations, frequency versus amplitude was plotted resulting in a feature space.

The feature space of laboratory data presented in Figure 13 showed exclusive clusters between bonded and unbonded conditions. It was also observed that unbonded condition exhibited two different clusters depending on temperature condition, yet none of them coincided with bonded condition. This was a good indicator that the features, peak frequency, and its amplitude were good parameters to indicate interlayer condition and it was not affected by temperature dependence of asphalt concrete.

The feature space of the field data, on the other hand, was presented in Figure 14. In this feature space, the points from heaved section and $50 \%$ of the points of severe condition displayed consistent clustering at $500 \mathrm{~Hz}$. Around $61 \%$ of the points of good condition and $76 \%$ of the points of minor condition were clustered in $1,100 \mathrm{~Hz}$.

It was noted in field data that the hitting point selected for sounding test and the measurement point of deterioration after water jet may not exactly coincide with each other resulting in some error in validation. Figure 11(b) showed that rapid changes in the condition of concrete surface may cause possible error in comparing sounding test result and visual inspection.

In Figure 15, a generalized decision matrix was proposed for use in the analysis of interlayer condition. From the feature space of the laboratory and field tests, four zones identifying the different levels of interlayer condition were proposed. Each zone was bounded by significant peak frequency range observed in the laboratory and in the field tests.

As shown in Figure 15, the results of laboratory and field data were plotted in the proposed decision matrix where data points were clustered in four different zones. The data points clustered in Zone a were the high temperature unbonded condition of laboratory data, the points from heaved section, 


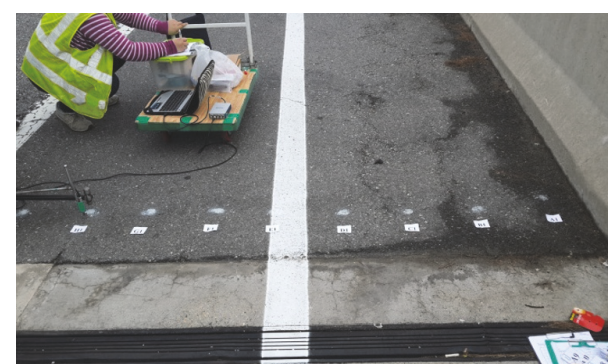

(a)

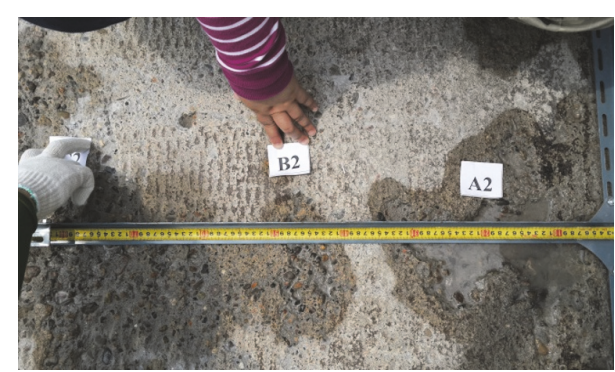

(b)

FIGURE 11: Impact sounding test performed in Yanggok Bridge in South Korea before asphalt concrete overlay rehabilitation: (a) sounding test; (b) measuring delamination after water jet.

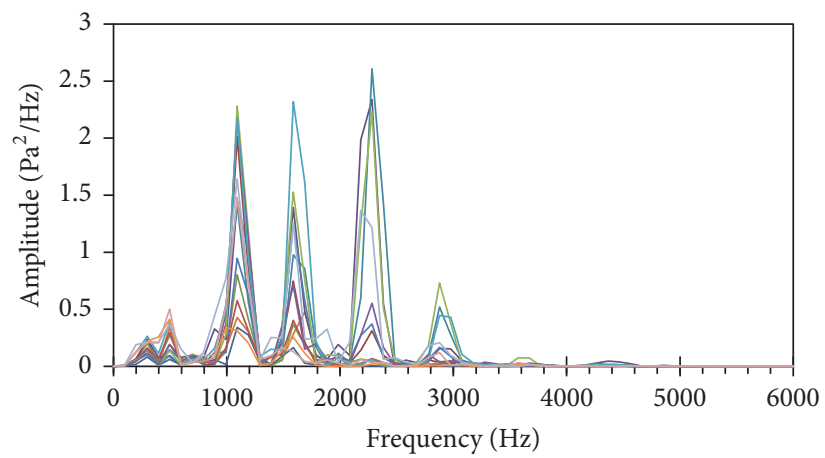

(a)

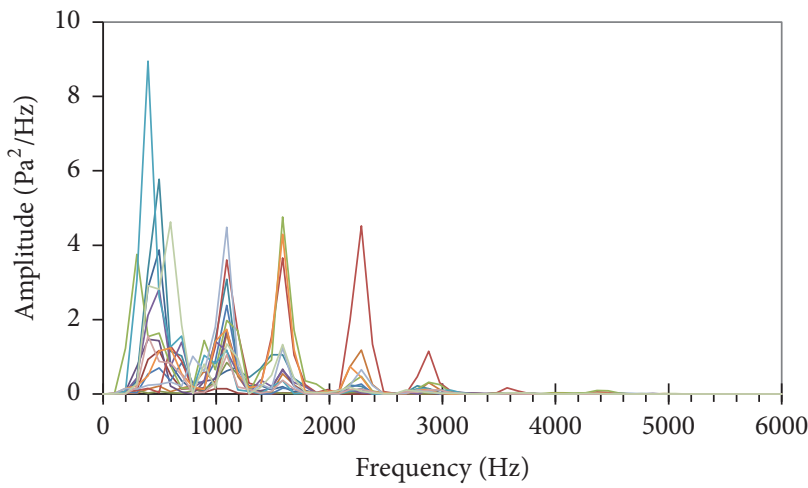

(c)

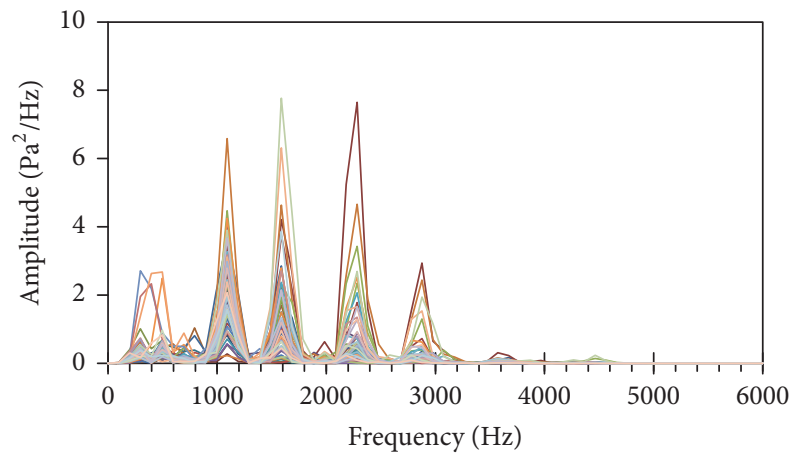

(b)

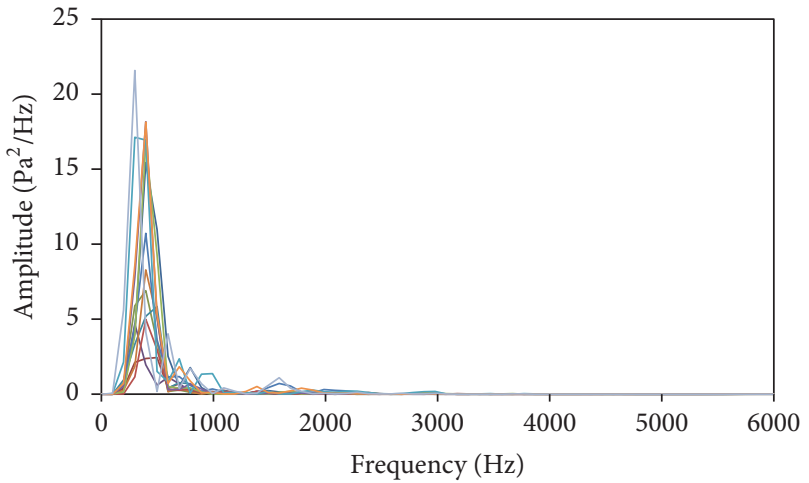

(d)

FIGURE 12: Combined frequency spectra of different points depending on condition level: (a) good condition; (b) minor condition; (c) severe damage; (d) heaved sections.

and the $50 \%$ of severe damage points in field data. In Zone $b$, points collected from low temperature unbonded condition of laboratory data were grouped. In Zone c, on the other hand, $61 \%$ of the data points were from good condition assessment and $76 \%$ of data points were from the minor damage in the field data condition assessment. Lastly, points in Zone $d$ were data points from bonded slab data including $21 \%$ of data points from good condition and $10 \%$ of data points from minor damage condition of field data.

Table 4 summarized the description of the decision matrix as well as the interlayer conditions observed during the field test. Zone a data points showed severe damage condition wherein, aside from completely detached asphalt concrete interlayer, pothole-like damage was observed from the cement concrete bridge deck. Compared with previous condition assessment presented in Table 2, the proposed Zone $a$ of the decision matrix represented combined characteristics of severe damage and heaved condition as observed both in the field and in the laboratory. Thus, laboratory field test was able to simulate the field condition.

In Zone $b$, on the other hand, the interlayer condition displayed a completely detached asphalt concrete but no damage on the cement concrete layer. This characteristic of Zone $c$ is inherent with minor condition assessment mentioned in Table 2. However, the data points identified in this zone were from the laboratory specimen of unbonded condition 
TABLE 4: Summarized description of the proposed zonal condition level of bridge deck pavement.

\begin{tabular}{|c|c|c|c|}
\hline \multirow{2}{*}{ Zone } & \multirow{2}{*}{ Condition } & \multicolumn{2}{|c|}{ Description } \\
\hline & & Frequency spectra & Visual inspection \\
\hline a & Severe & Peak frequency less than $600 \mathrm{~Hz}$ & $\begin{array}{c}\text { Deterioration depth is greater than } 25 \mathrm{~mm} \\
\text { Asphalt concrete is heaved } \\
\text { Traces of moisture are remarkable }\end{array}$ \\
\hline $\mathrm{b}$ & Debonded & $\begin{array}{l}\text { Peak frequency of } 1,000 \text { to } 1,300 \mathrm{~Hz} \text {, peak } \\
\text { amplitude higher than } 50 \mathrm{~Pa}^{2} / \mathrm{Hz}\end{array}$ & $\begin{array}{l}\text { Asphalt concrete is completely detached from the } \\
\text { concrete deck }\end{array}$ \\
\hline c & Fair & $\begin{array}{l}\text { Peak frequency of } 1,000 \text { to } 1,300 \mathrm{~Hz} \text {, peak } \\
\text { amplitude lower than } 50 \mathrm{~Pa}^{2} / \mathrm{Hz}\end{array}$ & Surface of concrete deck shows minor scaling \\
\hline d & Good & Peak frequency higher than $1,500 \mathrm{~Hz}$ & $\begin{array}{c}\text { Good condition, no inspected damage on the surface of } \\
\text { concrete deck }\end{array}$ \\
\hline
\end{tabular}

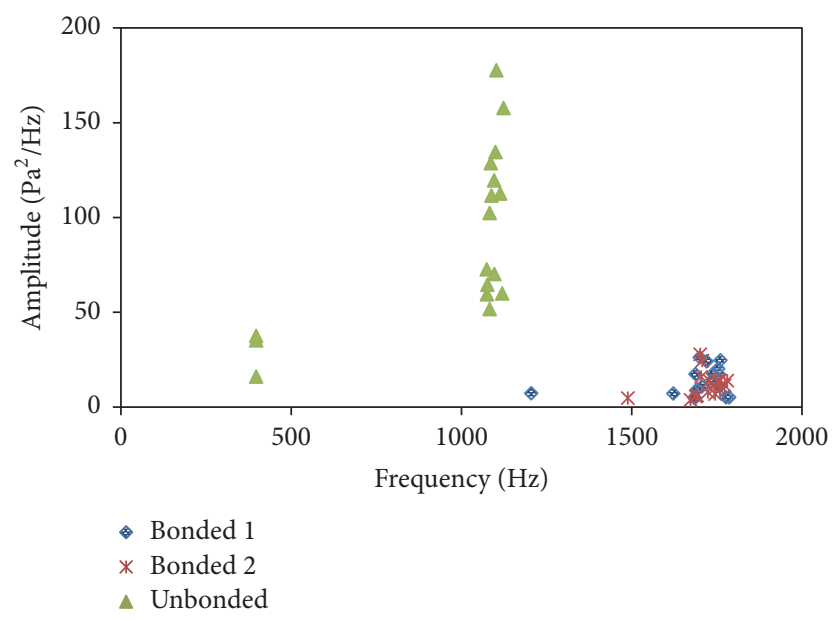

FIGURE 13: Feature space of interlayer bonding condition in the laboratory setup.

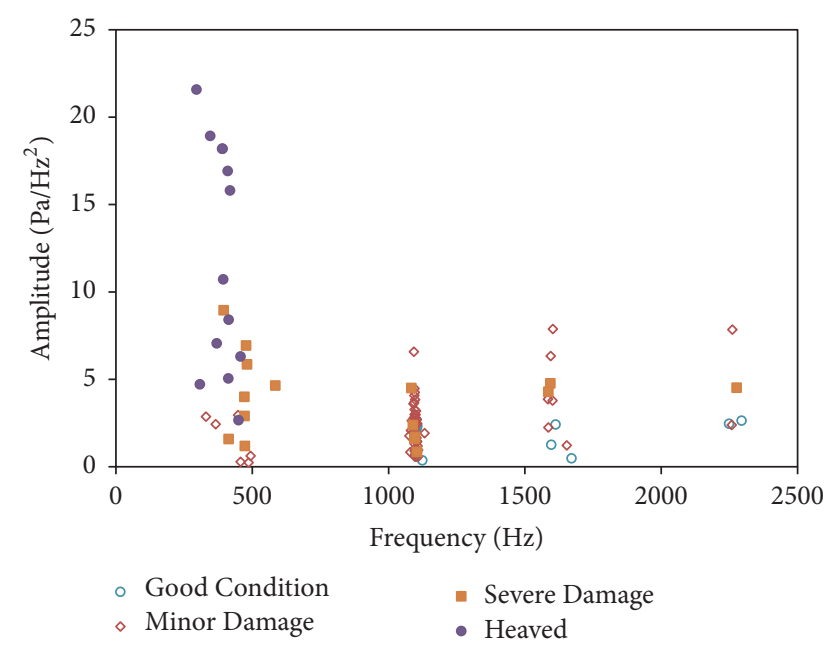

FIgURE 14: Feature space of interlayer condition in the field.

at high temperature. Thus, more field tests were needed to be performed to validate this condition. In the same way, the Zone $c$ of the decision matrix was composed of both good and minor condition assessment of data points in the field. This showed that Zone $c$ was a new interlayer condition identified

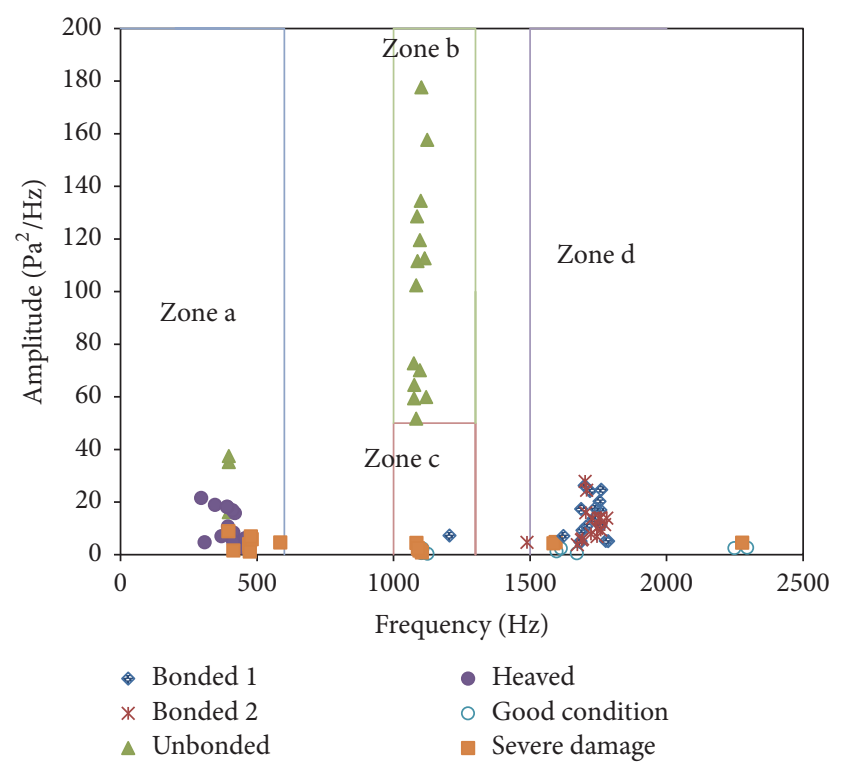

FIGURE 15: Decision matrix of interlayer condition in the laboratory and in the field.

using sounding test method. This condition poses critical transition of interlayer condition from good to debonded condition, meaning, at this state, interlayer section started to develop debonding. Lastly, the Zone $d$ of the decision matrix showed no damage on the interlayer section of the concrete bridge deck. The data points belonging to Zone $d$ were points showing complete bonding and no interlayer damage. Low percentage of good condition data from the field shows that the concrete bridge deck was subjected to traffic and environmental stress and rehabilitation was really needed.

\section{Summary and Conclusion}

In this study, a simple and direct approach to identify the interlayer condition between concrete bridge deck and asphalt pavement using sounding tests was proposed. It was observed from an extensive laboratory and field experiments that peak amplitude and peak frequency of sounding data in frequency domain were good parameters for determining 
interlayer bonding condition. These parameters were dependent such that peak amplitude and peak frequency of data points collected in the laboratory and in the field were plotted in a feature space. Consequently, a proposed generalized decision matrix approach based on the feature space was presented in this study. In this approach, overall analysis of data by clustering of points resulted in four different zones which can describe the interlayer conditions. The proposed analysis was capable of detecting intermediate conditions interlayer, which emphasized the transition of damage in interlayer section. Although the proposed decision matrix analysis of sounding test method was feasible in determining interlayer condition, further field studies are needed to validate the proposed decision matrix in this study.

\section{Conflicts of Interest}

The authors declare that they have no conflicts of interest.

\section{Acknowledgments}

This research was partially supported by a grant (17TLRPC099510-03) from Transportation \& Logistics Research Program (TLRP) funded by the Ministry of Land, Infrastructure, and Transport of Korean Government and the Seoul Metropolitan Government.

\section{References}

[1] T. W. Kim, J. Baek, H. J. Lee, and S. Y. Lee, "Effect of pavement design parameters on the behaviour of orthotropic steel bridge deck pavements under traffic loading," International Journal of Pavement Engineering, vol. 15, no. 5, pp. 471-482, 2014.

[2] B. Pouteau et al., FABAC accelerated loading test of bond between cement overlay and asphalt layers, in Pavement Cracking, CRC Press, 2008.

[3] L. Shao, Y. Li, and L. Zhang, "Research of structural properties of asphalt pavement system on orthotropic steel bridge deck in full scale tests," in Proceedings of the 2nd International Conference on Accelerated Pavement Testing, p. 16, 2004.

[4] EAPA, Asphalt pavements on bridge decks. 2013, EAPA. p. 33.

[5] ASTM, "D4580/D4580M-12: standard practice for measuringdelaminations in concrete bridge decks by sounding," in Proceedings of the ASTM Volume 04.03 Road and Paving Materials; Vehicle Pavement Systems., , ASTM International, West Conshohocken, PA, USA, 2012.

[6] ASTM, "D4788-03: Standard Test Method for DetectingDelaminations in Bridge Decks Using Infrared Thermography," in Proceedings of the ASTM Volume 04.03 Road and Paving Materials; Vehicle Pavement Systems. 2007, ASTM International, Conshohocken, PA, USA, 2007.

[7] ASTM, "D6087-08: Standard Test Method for Evaluating Asphalt-Covered Concrete Bridge Decks Using Ground Penetrating Radar," in Proceedings of the ASTM Volume 04.03 Road and Paving Materials; Vehicle Pavement Systems. 2008, ASTM International, Conshohocken, PA, USA, 2008.

[8] M. K. Heitzman et al., "Nondestructive Testing to IdentifyDelaminations Between HMA Layers," in Transportation Research Board: 500 Fifth St, Washington, DC, USA, 2013.
[9] T. Saarenketo and T. Scullion, "Road evaluation with ground penetrating radar," Journal of Applied Geophysics, vol. 43, no. 24, pp. 119-138, 2000.

[10] M. Celaya et al., "Delamination detection of HMA airport pavements with NDT devices," in Proceedings of the FAA Worldwide Airport Technology Transfer Conference, 2010.

[11] D. Munoz, "Finite Element Modeling Of Non-destructive Test Methods Used For Detection of Delamination In Hot Mix Asphalt Pavements," in The University of texas in El Paso: El Paso, p. 67, 2009.

[12] M. E. Henderson et al., Acoustic inspection of concrete bridge decks, SPIE, 1999.

[13] Y. Lu, Y. Zhang, Y. Cao, J. Gregory McDaniel, and M. L. Wang, "A mobile acoustic subsurface sensing (MASS) system for rapid roadway assessment," Sensors (Switzerland), vol. 13, no. 5, pp. 5881-5896, 2013.

[14] T. Suda, A. Tabata, J. Kawakami, and T. Suzuki, "Development of an impact sound diagnosis system for tunnel concrete lining," Tunnelling and Underground Space Technology, vol. 19, no. 4-5, pp. 328-329, 2004.

[15] G. Zhang, R. S. Harichandran, and P. Ramuhalli, "Application of noise cancelling and damage detection algorithms in NDE of concrete bridge decks using impact signals," Journal of Nondestructive Evaluation, vol. 30, no. 4, pp. 259-272, 2011.

[16] MDOT, Instruction Manual for Bridge Deck Delamination Detector, Michigan Department of Transportation, Lansing, Mich, USA, 1977.

[17] B. L. Giordano and S. McAdams, "Material identification of real impact sounds: Effects of size variation in steel, glass, wood, and plexiglass plates," Journal of the Acoustical Society of America, vol. 119, no. 2, pp. 1171-1181, 2006.

[18] S. McAdams, A. Chaignec, and V. Roussarie, "The psychomechanics of simulated sound sources: Material properties of impacted bars," Journal of the Acoustical Society of America, vol. 115, no. 3, pp. 1306-1320, 2004.

[19] A. M. Alexander et al., Impacts as a Source of Acoustic Pulseecho Energy for Nondestructive Testing of Concrete Structures, U.S. Army Engineer Waterways Experiment Station, 1993.

[20] R. B. Randall, Frequency analysis, Brüel \& Kjaer, 1987.

[21] F. Tong, S. K. Tso, and X. M. Xu, "Tile-wall bonding integrity inspection based on time-domain features of impact acoustics," Sensors and Actuators, A: Physical, vol. 132, no. 2, pp. 557-566, 2006.

[22] S. X. Liu, F. Tong, B. L. Luk, and K. P. Liu, "Fuzzy pattern recognition of impact acoustic signals for nondestructive evaluation," Sensors and Actuators, A: Physical, vol. 167, no. 2, pp. 588-593, 2011.

[23] J. S. Popovics, "Investigation of a Full-Lane Acoustic Scanning Method for Bridge Deck Nondestructive Evaluation," Transportation Research Board, 2010.

[24] M. Sansalone and W. B. Streett, Impact-echo: non-destructive evaluation of concrete and masonry, Bullbrier Press, 1997.

[25] M. Sansalone and N. J. Carino, "Detecting delaminations in concrete slabs with and without overlays using the impact-echo method," ACI Materials Journal, vol. 86, no. 2, pp. 175-184, 1989.

[26] F. Fahy and P. Gardonio, "Sound and Structural VibrationRadiation, Transmission and Response," Noise Control Engineering Journal, vol. 55, no. 3, p. 373, 2007.

[27] J. W. S. Rayleigh and R. B. Lindsay, The Theory of Sound, Dover Publications, New York, NY, USA, 1945. 


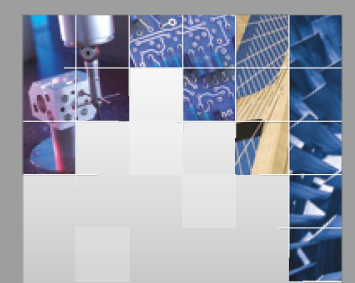

\section{Enfincering}
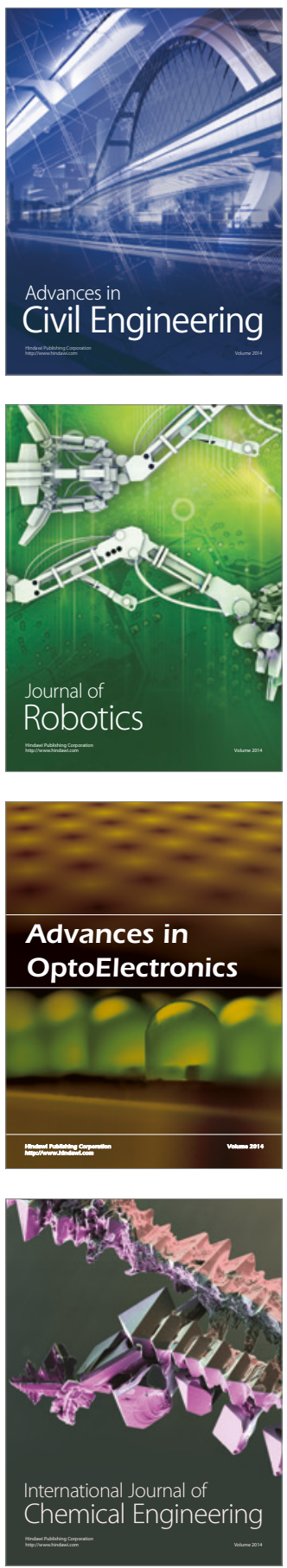

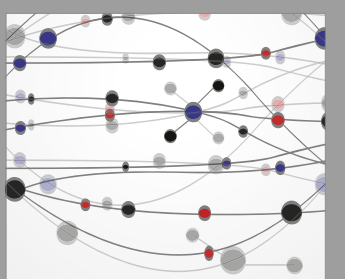

The Scientific World Journal

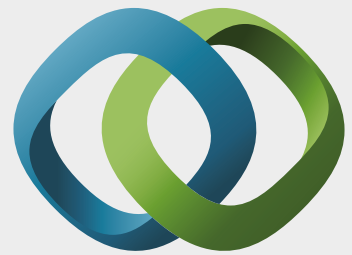

\section{Hindawi}

Submit your manuscripts at

https://www.hindawi.com
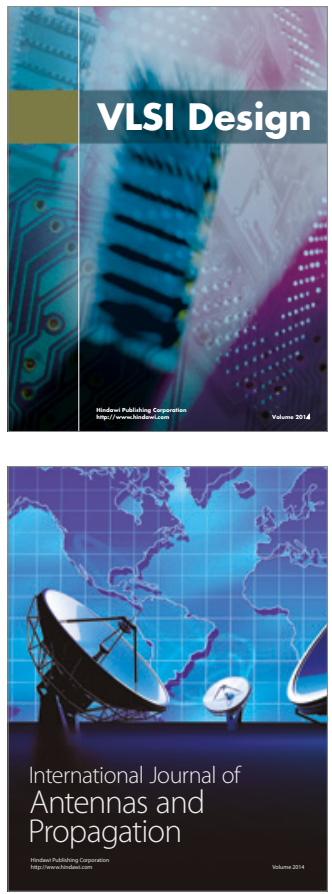

\section{Rotating}

Machinery
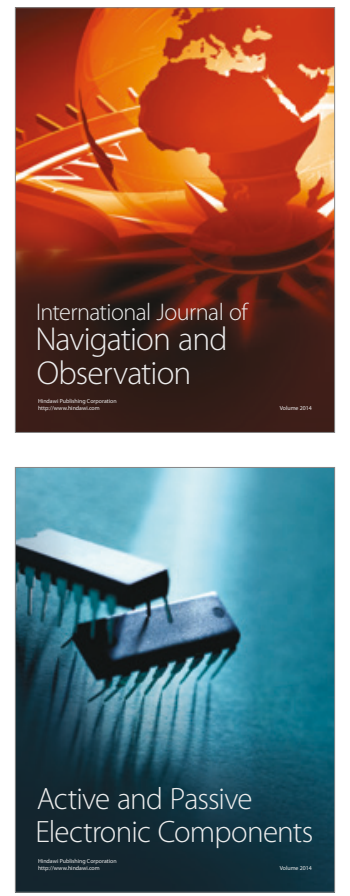
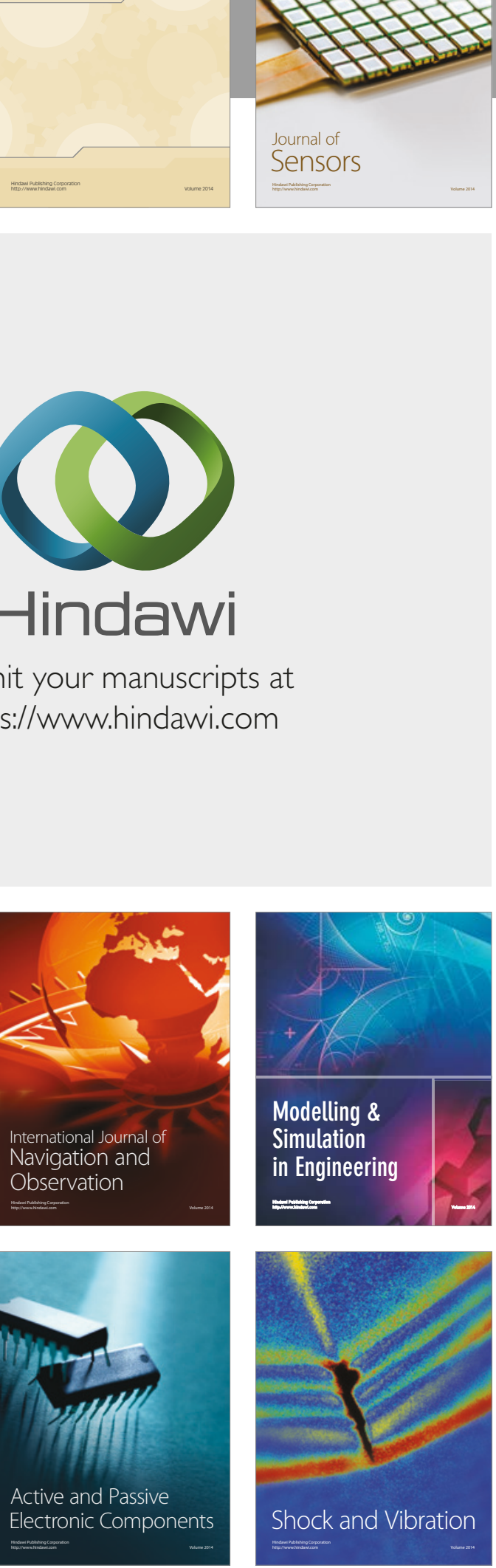
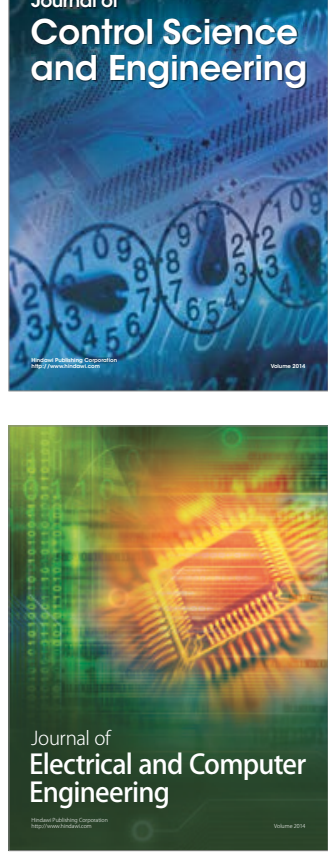

Distributed

Journal of

Control Science

and Engineering
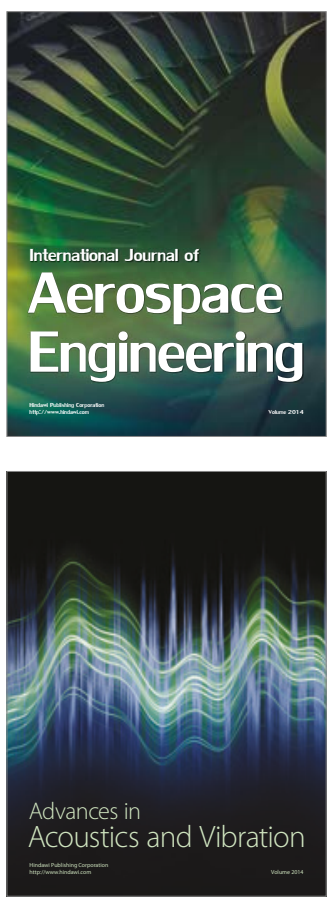

Sensor Networks 